\title{
Image Enhancement Based on Fan Filter Parameters Adjustment
}

\author{
Huda S. Mustafa \\ hudasalih95@gmail.com \\ Computer Science, \\ Nineveh General Directorate of Education
}

Received on: 27/09/2020

Accepted on: 21/12/2020

\section{ABSTRACT}

In the field of image processing, there is an urgent need to adopt image transformations. In this paper, work is done on image coefficients after decomposing them through Curvelet transformations obtained through the fan filter.

The research deals with two stages: the first is to study the effect of the Fan filter by adopting angles $(8,16,32)$ on the image (Lina.jpg) of size $\left(256^{* 256}\right)$ after being analyzed using Curvelet transformations at scales $(2,3,4)$ through comparing a set of measurements (Contrast, Energy, Correlation, MSE, and PSNR) for both the original and reconstructed images. It can be found that Contrast and Energy criteria remain the same for the original and reconstructed images according to different levels of analysis or directions, so the value of the Correlation measure is 1 . The value of the MSE criterion is very small and is almost not affected by the change of the number of angles in one scale, but it is slightly affected by increasing the scale analysis. What was mentioned above applies to the PSNR criterion as well.

As for the second stage of the research, which included decomposing the image to its coefficients, canceling the effect of one of these coefficients, and then reconstructing it. The results proved that the two criteria (Contrast and Energy) were not affected with falling Correlation criteria from 1 to values ranging from (0.9987_0.9997) depending on the number of scales used in the Curvelet analysis and the number of angles used in Fan filter (8,16,32). The results also showed an increase in the MSE value when dropping some frequencies, and a corresponding decrease in the PSNR value. Whereas, the decrease in the MSE scale was demonstrated at a specific scale with the increase in the number of angles in the Fan filter, in contrast to the PSNR scale.

Keywords: Curevlet Transform, Fan Filter, Curvelet Coefficients.

\section{Introduction}

As rapid developments in the last decades in information techniques that lead to the creation of enormous amounts of data images in various domains such as Exhibitions of fine arts, fashion design, medicine, and more. There was a need to innovate an effective method to retrieve image information to perform a special task and make an appropriate decision. The Curvelet Transform is one of the latest technologies that deal with the above [16].

In the field of image processing, a minimum number of non-zero coefficients can accurately represent the unique properties of the image curve. After analyzing the image using the Curvelet transform, most of the image information is concentrated in the coefficients. The energy is also more concentrated, which results from analyzing the important characteristics of the image such as edge and composition.[3]

This research aims to present a study and comparison between the studied image characteristics before and after the analysis by Fan filter supported by Curvelet 
transform. And study the effect of zeroing one of the analyzed image coefficients on the characteristics of the original and recovered images.

2. Related Works In 2012, Jie $\mathrm{Hu}$ and et. al. provided an automatic optimization of SAR images based on the Curvelet transform and genetic algorithm trying to find the best image. The experimental results showed that the proposed method could improve edge properties, the contrast of SAR images, reduce speckle noise, and thus outperformed the non-automatic optimization methods [4].

Also, in 2012, Nilima and Wani presented a method to compare image compression using wavelet transform with Curvelet transform and then sent an image across the wireless channel. The goal of this research is to analyze the compression using both transforms. Curvelet transform gave results better than Wavelet transform in PNSR ratio especially by selecting threshold effectively [15].

Furthermore, Mohamed and et. al. presented, in 2012, an evaluation for the second generation of Curvelet Transform as a tool to determine the curves, which had been compared with Wavelet Transform and detecting curves using Canny. The proposed algorithm was executed using Curvelet Transform on Satellite images with high accuracy and then it was reused with Wavelet Transform and Canny [13].

Vaghela presented, in 2013, a method to retrieve images using Curvelet transform to get efficient retrieval and good stability with less complexity in calculations performance. The researcher used Curvelet transform with index components through Scale, Location, and Orientation parameters according to Scaling Law [21].

In 2014, Kaizhi Wu and et. al. implemented the principle of similarity between the two pixels of the distorted image with noise and the image reconstructed using the Curvelet transform to obtain the final result of the image without noise using the nonlocal method [5].

Also, in 2014, Tirveedi P. and Pullarao Ch. presented their research to design and improve image accuracy using zeros padding. The algorithm used a Curvelet Transform to split the image into more than one scale, then add the high-frequency images, and then combine all the images using the inverse of the Curvelet Transform (IDFCT) to form the image [20].

In the last recent years, Abdalla M. and et. al. presented and discussed different techniques to remove noise from color images. They also got and compared the results for different filter techniques. The results produced from the median filter ensure that the image would be free of noise besides it kept its finesse [1].

In 2019, Karam, Eman, and Khalil presented research providing a new method to design a filter for high frequencies and studying the influence of those coefficients by dropping some of them and then recreate the image from the remaining coefficients. The proposed algorithm was applied on different types of images with different amounts of frequencies [6].

In 2020, Hui Zhang and et. al. suggested a fusion method with PCNN (PulseCoupled Neural Network) model for the infrared and visible images to improve night vision or bad vision conditions. They used a guided filter and composed images by Curvelet Transform [3].

\section{Curvelet Transform and Fan Filter}

The Curvelet Transform is a mathematical transformation with more than one scale and it provides a multi-precision representation with several properties that override existing representations such as the Wavelet. The idea of Curvelet Transform is 
to split the signal into several sub-bands at different scales with different directions and locations in the frequency domain as they are described using the scaling law [22].

Curvelet Transform has localization properties of time-frequency as in Wavelet but it appears in a high degree of orientation and variant besides its singularities properties that can be estimated approximately in a few numbers of coefficients [19]. There is no loss of information at using Curvelet. Hence, the image is segmented into groups of wave sub-bands, each band can be analyzed using Ridgelet transform and image mass can be changed at every scale. The attributes are very similar to the expected results from the orthonormal property, which reflects obvious stability in representation [2]. Curvelet Transform was built relying on multiscale Ridgelet Transform and then merged them with filtering operation depending on the bands to isolate different measures [18].

When applying Curvelet Transform at fast discrete type using wrapping technique for multiscale analyzing, image is divided into a series of unrelated bands that creates Curvelet coefficients. The bands are divided into three main groups: coarse scale, detail scale, and fine-scale. The deepest scale is the coarse-scale that contains low-frequency coefficients reflecting general information and main energy in the image. The furthest scale is a fine-scale that contains high-frequency coefficients reflecting detailed information and edge lawns of image. The remaining scales are classified as details scale that contains moderate-high coefficients and besides show edge detail image information [17]. The characteristics of Curvelet Transform can be summarized as follows [9]:

1. Most of the image energy resides in the low bands while the rest of the energy diffuses into the other bands decreasing from low to high frequencies.

2. Maximum value of coefficient settled at the first level.

3. Minimum value of coefficient settled in the last level.

4. At an increasing number of the scale, coefficients will contain more zero values.

5. Curvelet coefficients have strong directional properties.

In 1992, Smith and Bamberger presented a two Directional Filter Bank (DFB) that was represented by analysis structure: L-level which leads to $2^{\mathrm{L}}$ of branches in the wedge-shaped while spaces between wedges represent department frequencies, as shown in Figure (1). If $\mathrm{L}=3$, there were $2^{3}=8$ wedge branches in the wedge-shaped [14].

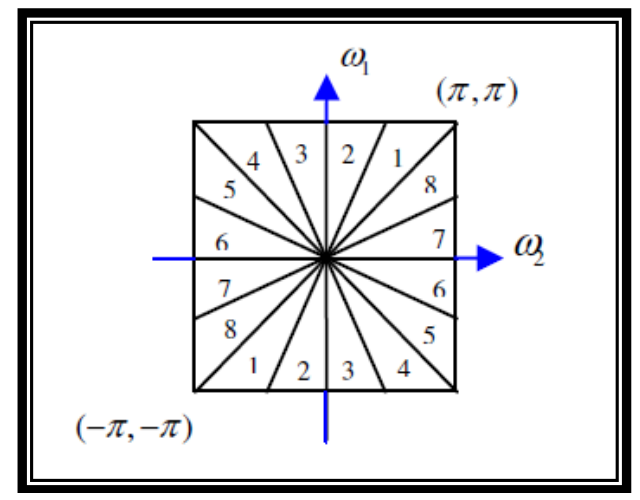

Figure (1): Frequency branches for DFB, which represent wedge-shaped 
The original structure for DFB included consisting operation or modulating for entered image and using Quincunx Filter Bank (QFB) with rhombic shaped filters. Analysis operation was complex [8].

In recent research, a simple new structure of DFB that relies only on QFB with Fan filters has been adopted. This new formula moves away from the inclusion process of the input image and has a simpler structure in the analysis process [8].

A new version for DFB consists of two structures. The first contains two channels; both have QFB with Fan filter, as in Figure (2). It also divides the twodirectional frequency spectrum into two directions: vertically and horizontally [8].

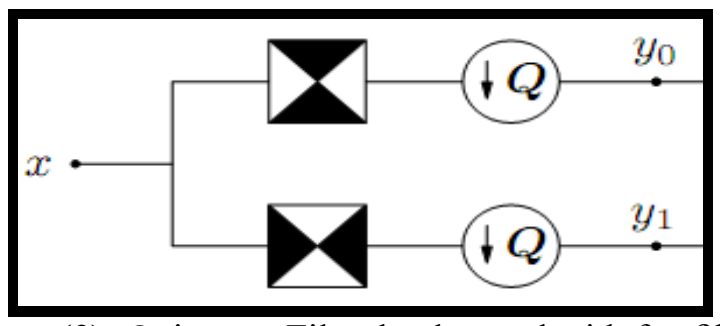

Figure (2): Quincunx Filter banks used with fan filters

The second structure for DFB consists of a pair of shearing operator operations in which each operation to channel of DFB that rearrange image samples only. It rotates the image without changing in data value [12].

The image will get two different directions. As a result, it is possible to achieve frequency sections by merging directional frequency sections, which has created in Fan filter of QFB, and directional frequency sections resulted from rotation operation that used Shearing operation [12].

\section{Performance Evaluation Metrics:}

a. Contrast is defined as the difference in the amount of illumination between the brightest point and the darkest point in an image. It can be calculated by Eq. (1) [7]:

Contrast for image in grayscale $=\sum|i-j|^{2} * P_{\text {image }}(i, j) \quad i, j=0,1,2$

$P(i, j)$ : the value of the pixel in an image at location $i$-row and $j$-column.

b. Energy: To define energy, we say that the bodies possess an amount of brightness represented by a numerical value, which represents the energy level of that point [10] and can be calculated mathematically by eq. (2) [11]:

$$
\text { Energy for image in grayscale }=\sum \mathrm{P}^{2}{ }_{\text {image }}(\mathrm{i}, \mathrm{j}) \quad \mathrm{i}, \mathrm{j}=0,1,2
$$

c. Correlation $=\operatorname{corr} 2(\mathrm{~K}, \mathrm{~L})$, which indicates how close the original image $(\mathrm{K})$ and the distorted image $(\mathrm{L})$ are. If correlation is 1 , there is no difference between them and it can be evaluated by the eq.(3) [11]:

$$
\text { corr } 2=\frac{\sum_{m} \sum_{n}\left(K_{m n}-K^{\prime}\right)\left(L_{m n}-L^{\prime}\right)}{\sqrt{\left(\sum_{m} \sum_{n}\left(K_{m n}-K^{\prime}\right)^{2}\right)\left(\sum_{m} \sum_{n}\left(L_{m n}-L^{\prime}\right)^{2}\right)}}
$$$$
\mathrm{n}=0,1,2
$$

where $\mathrm{K}^{\prime}, \mathrm{L}^{\prime}$ are averages of the values in $(\mathrm{K})$ and $(\mathrm{L})$ consecutively.

d. MSE is an abbreviation of Mean Square Error that can be calculated for two grayscale images $\mathrm{K}$ and $\mathrm{L}$, where $\mathrm{K}$ is the original image in grayscale while $\mathrm{L}$ is the noisy(distorted) image close to the original image. Eq. (4) shows the evaluation [ 15]:

$$
\mathrm{MSE}=\frac{1}{M . N} \sum_{i=0}^{M-1} \sum_{j=0}^{N-1}(K(i, j)-L(i, j))^{\wedge} 2
$$


Where $\mathrm{M}$ and $\mathrm{N}$ are the number of rows and columns in the input image, respectively. $\mathrm{K}$ : Original image; L: Recovered image.

e. PSNR is an acronym for Peak Signal to Noise Ratio that is a scale for image quality for each state. It is the most widely used as a measure of the quality of image retrieval. It can be easily found using MSE. eq. (5) shows the evaluation [15]:

$$
\mathrm{PSNR}=10 * \log _{10}\left(\frac{M \cdot M}{M S E}\right) \quad \mathrm{M} \text { : number of rows }=\text { number of columns }
$$

\section{Proposed Algorithm}

The algorithm has been proposed in this research depending on the principle of Curvelet Transform and Fan filter to study the properties for both of the original image and recovered image after using this transformation by using different levels. It is consists of two stages:

First Stage: It boils down to the steps:

1. Acquiring the image and then converting it to grayscale.

2. Calculating Contrast, Energy, Correlation, MSE, and PSNR parameters for the original image.

3. Analyzing the image using Fan filter with Curvelet transform to its coefficients at different scales.

4. Reconstructing the image from its coefficients.

5. Calculating Contrast, Energy, Correlation, MSE, and PSNR parameters for the recovered image.

6. Comparing the results of the original image with the image after compositing.

Second Stage: It is the same steps as the first part, only the difference is by taking one of the coefficients of the analyzed image (in paragraph 3) and dropping that coefficient by making its values zero. After the image is reconstructed, the parameters of the recovered image are calculated and compared with parameters of the origin to see the effect of that coefficient.

\section{Result and Discussion on Applied Example:}

Lina.jpg image at size $256^{*} 256$ shown in Figure (3) was chosen to study the performance of the proposed algorithm.

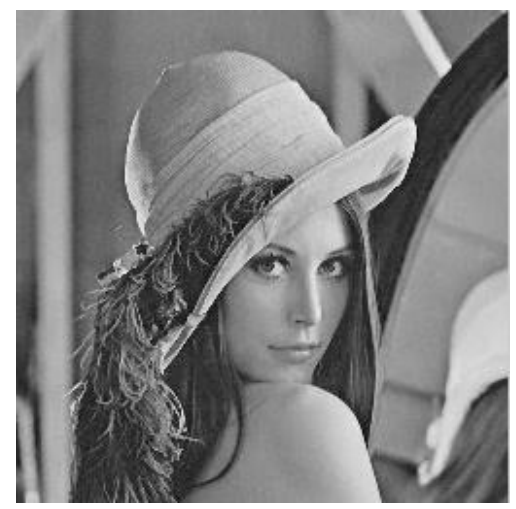

Figure (3): The Original Image 


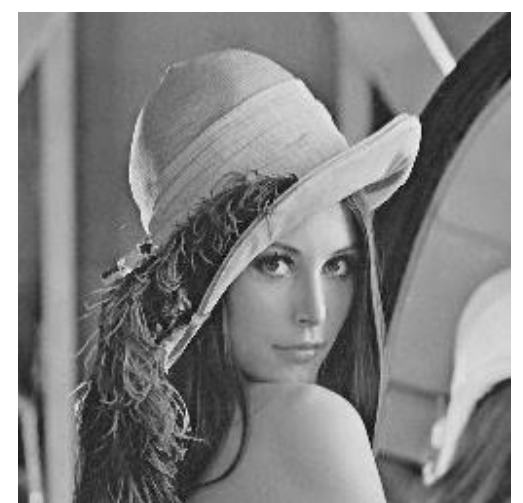

(a)

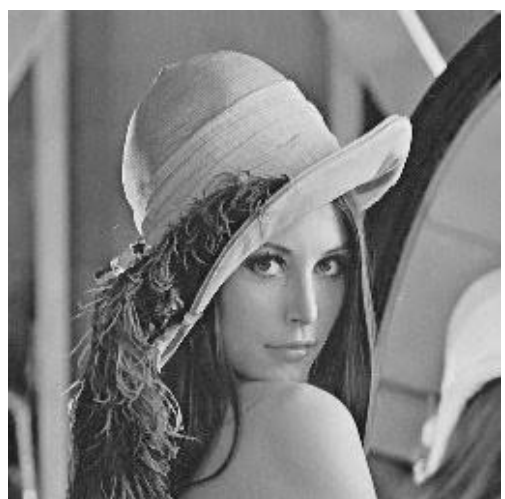

(b)

Figure (4): The Reconstructed Image (a) First stage; (b) Second stage

Then it is converted into grayscale to be analyzed by Curvelet transform with Fan filter to its coefficients in case of no. of scales $=2$; no. of angles $=8$. As a result, the total number of coefficients will be 9 (as shown in Figure (5): one of the coefficients is in the first scale, and 8 in the second.

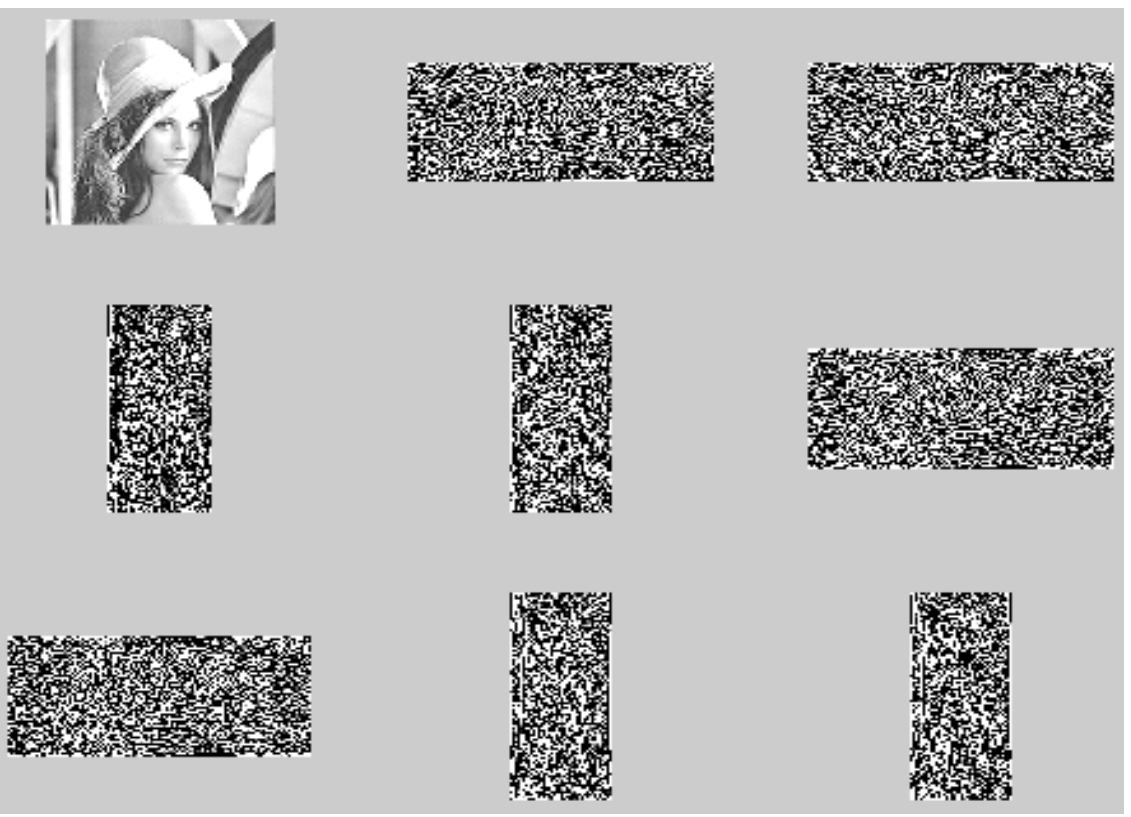

Figure (5): Curvelet Coefficients

First Stage: Under the following conditions: no. of scales=2,3,4 and the number of angles $=8,16,32$ are taken separately for each scale to evaluate parameters for both the original and the reconstructed images (Figure 4.a) and the results are recorded in the Table (1):

Table (1): Parameters Evaluation for image size $256 * 256$

\begin{tabular}{|l|c|c|c|c|c|c|c|c|c|}
\hline & \multicolumn{3}{|c|}{ Scale 2 } & \multicolumn{3}{c|}{ Scale 3 } & \multicolumn{3}{c|}{ Scale 4} \\
\hline $256^{*} 256$ & $\begin{array}{c}8 \\
\text { angles }\end{array}$ & $\begin{array}{c}16 \\
\text { angles }\end{array}$ & $\begin{array}{c}32 \\
\text { angles }\end{array}$ & $\begin{array}{c}8 \\
\text { angles }\end{array}$ & $\begin{array}{c}16 \\
\text { Angles }\end{array}$ & $\begin{array}{c}32 \\
\text { angles }\end{array}$ & $\begin{array}{c}8 \\
\text { Angles }\end{array}$ & $\begin{array}{c}16 \\
\text { angles }\end{array}$ & $\begin{array}{c}32 \\
\text { angles }\end{array}$ \\
\hline Contrast & $8.34 \mathrm{E}+10$ & $8.34 \mathrm{E}+10$ & $8.34 \mathrm{E}+10$ & $8.34 \mathrm{E}+10$ & $8.34 \mathrm{E}+10$ & $8.34 \mathrm{E}+10$ & $8.34 \mathrm{E}+10$ & $8.34 \mathrm{E}+10$ & $8.34 \mathrm{E}+10$ \\
\hline Energy & $1.16 \mathrm{E}+09$ & $1.16 \mathrm{E}+09$ & $1.16 \mathrm{E}+09$ & $1.16 \mathrm{E}+09$ & $1.16 \mathrm{E}+09$ & $1.16 \mathrm{E}+09$ & $1.16 \mathrm{E}+09$ & $1.16 \mathrm{E}+09$ & $1.16 \mathrm{E}+09$ \\
\hline Correlation & 1 & 1 & 1 & 1 & 1 & 1 & 1 & 1 & 1 \\
\hline MSE & $1.58 \mathrm{E}-27$ & $1.58 \mathrm{E}-27$ & $1.58 \mathrm{E}-27$ & $3.28 \mathrm{E}-27$ & $3.31 \mathrm{E}-27$ & $3.28 \mathrm{E}-27$ & $2.00 \mathrm{E}-27$ & $1.98 \mathrm{E}-27$ & $2.05 \mathrm{E}-27$ \\
\hline PSNR & $3.16 \mathrm{E}+02$ & $3.16 \mathrm{E}+02$ & $3.16 \mathrm{E}+02$ & $3.13 \mathrm{E}+02$ & $3.13 \mathrm{E}+02$ & $3.13 \mathrm{E}+02$ & $3.15 \mathrm{E}+02$ & $3.15 \mathrm{E}+02$ & $3.15 \mathrm{E}+02$ \\
\hline
\end{tabular}


It can be observed from these results that Contrast and Energy for both original and recovered images retain their values, and they are insusceptible at different scales: 2, 3, 4; and different angles: 8, 16, 32. The correlation remains 1 at different scales and angles. While MSE and PSNR parameters show a bit different at different scales but retaining their values at different angles.

Second Stage: same steps are applied in the second stage. But, after analyzing the image, one of its coefficients (let be $C\{1,2\}\{1,1\}$ ) is dropped by making its values zero and then reconstructed the image (figure 4.b) to calculate parameters evaluation shown in Table (2):

Table (2): Parameters Evaluation after zeroing C $\{1,2\}\{1,2\}$ coefficient of size $256 * 256$

\begin{tabular}{|l|r|r|r|r|r|r|r|r|r|}
\hline & \multicolumn{3}{|c|}{ Scale 2 } & \multicolumn{3}{c|}{ Scale 3} & \multicolumn{3}{c|}{ Scale 4 } \\
\hline $256 * 256$ & $\begin{array}{c}8 \\
\text { angles }\end{array}$ & $\begin{array}{c}16 \\
\text { angles }\end{array}$ & $\begin{array}{c}32 \\
\text { angles }\end{array}$ & $\begin{array}{c}8 \\
\text { angles }\end{array}$ & $\begin{array}{c}16 \\
\text { angles }\end{array}$ & $\begin{array}{c}32 \\
\text { angles }\end{array}$ & $\begin{array}{c}8 \\
\text { Angles }\end{array}$ & $\begin{array}{c}16 \\
\text { angles }\end{array}$ & $\begin{array}{c}32 \\
\text { angles }\end{array}$ \\
\hline Contrast & $8.34 \mathrm{E}+10$ & $8.34 \mathrm{E}+10$ & $8.34 \mathrm{E}+10$ & $8.34 \mathrm{E}+10$ & $8.34 \mathrm{E}+10$ & $8.34 \mathrm{E}+10$ & $8.33 \mathrm{E}+10$ & $8.34 \mathrm{E}+10$ & $8.34 \mathrm{E}+10$ \\
\hline Energy & $1.16 \mathrm{E}+09$ & $1.16 \mathrm{E}+09$ & $1.16 \mathrm{E}+09$ & $1.16 \mathrm{E}+09$ & $1.16 \mathrm{E}+09$ & $1.16 \mathrm{E}+09$ & $1.161 \mathrm{E}+09$ & $1.2 \mathrm{E}+09$ & $1.2 \mathrm{E}+09$ \\
\hline Correlation & 0.99928 & 0.99957 & 0.99978 & 0.99912 & 0.99947 & 0.999736 & 0.99873 & 0.99919 & 0.99967 \\
\hline MSE & 3.40069 & 1.99842 & 1.029621 & 4.13143 & 2.47248 & 1.23974 & 5.98506 & 3.82088 & 1.57048 \\
\hline PSNR & 42.8491 & 45.1579 & 48.03803 & 42.0038 & 44.2335 & 47.23149 & 40.3941 & 42.3432 & 46.2045 \\
\hline
\end{tabular}

It is clear from the results of Table (2) that the Contrast and Energy kept their values at different scales and angles after dropping that coefficient. On the other hand, Correlation, MSE, and PSNR are affected by this event.

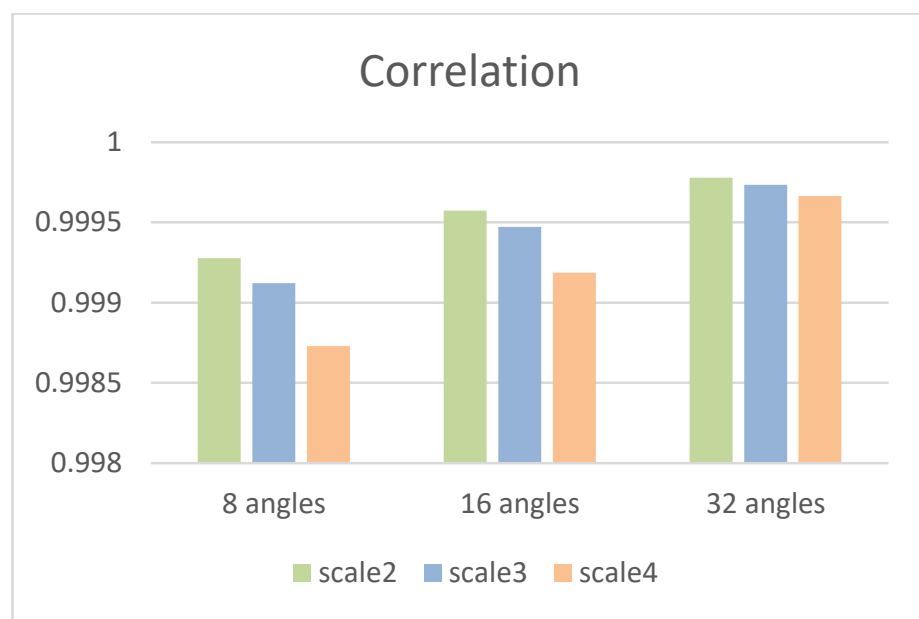

Figure (6): Correlation for Lina image of size $256 * 256$

As shown in Figure (6), Correlation became less than 1 instead of one after zeroing one of the image coefficients. It decreases as the scale increases. On the other hand, it increases in the determined scale at increasing angles (directions). 


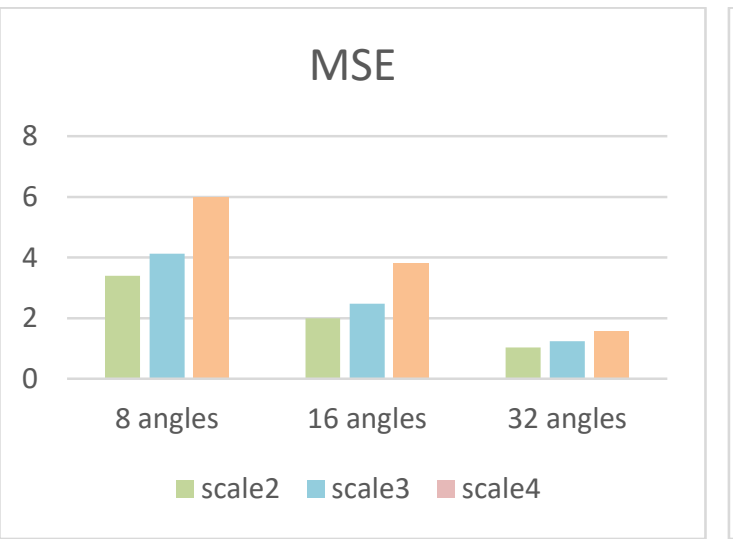

(a)

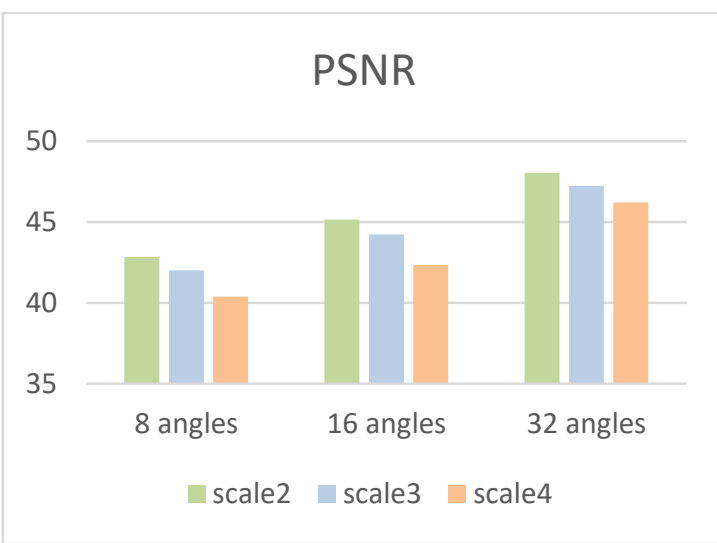

(b)

Figure (7): (a) MSE and (b) PSNR for Lina image of size 256*256

MSE and PSNR are related to each other, but the relationship between them is inverse, and this is evident from the results, and Figure (7) shows that. When the number of angles (directions) is fixed, MSE increases with increasing the scale number while PSNR decreases. If the number of scales is constant and the number of angles increases, a decrease in MSE and an increase in PSNR are noticed.

To verify that the algorithm works optimally, it was applied on the same image with different sizes $\left(128^{*} 128,512 * 512\right)$ and the results were as follows in the Table (3) \& (4) respectively:

Table (3): Parameters Evaluation after zeroing $C\{1,2\}\{1,2\}$ coefficient of size $128 * 128$

\begin{tabular}{|c|c|c|c|c|c|c|c|c|c|}
\hline $128 * 128$ & \multicolumn{3}{|c|}{ Scale2 } & \multicolumn{3}{c|}{ scale3 } & \multicolumn{3}{c|}{ Scale4 } \\
\hline & $\begin{array}{c}8 \\
\text { angles }\end{array}$ & $\begin{array}{c}16 \\
\text { angles }\end{array}$ & $\begin{array}{c}32 \\
\text { angles }\end{array}$ & $\begin{array}{c}8 \\
\text { angles }\end{array}$ & $\begin{array}{c}16 \\
\text { angles }\end{array}$ & $\begin{array}{c}32 \\
\text { angles }\end{array}$ & $\begin{array}{c}8 \\
\text { angles }\end{array}$ & $\begin{array}{c}16 \\
\text { angles }\end{array}$ & $\begin{array}{c}32 \\
\text { angles }\end{array}$ \\
\hline Contrast & $5.21 \mathrm{E}+09$ & $5.21 \mathrm{E}+09$ & $5.21 \mathrm{E}+09$ & $5.21 \mathrm{E}+09$ & $5.21 \mathrm{E}+09$ & $5.21 \mathrm{E}+09$ & $5.21 \mathrm{E}+09$ & $5.21 \mathrm{E}+09$ & $5.21 \mathrm{E}+09$ \\
\hline Energy & $2.88 \mathrm{E}+08$ & $2.88 \mathrm{E}+08$ & $2.88 \mathrm{E}+08$ & $2.88 \mathrm{E}+08$ & $2.88 \mathrm{E}+08$ & $2.88 \mathrm{E}+08$ & $2.88 \mathrm{E}+08$ & $2.88 \mathrm{E}+08$ & $2.88 \mathrm{E}+08$ \\
\hline Correlation & 0.99943 & 0.99969 & 0.99986 & 0.99869 & 0.99918 & 0.999665 & 0.9984881 & 0.99909 & 0.99945 \\
\hline MSE & 2.49453 & 1.33978 & 0.615464 & 5.77905 & 3.63031 & 1.472803 & 6.6867761 & 4.02197 & 2.4022 \\
\hline PSNR & 38.1743 & 40.8739 & 44.25217 & 34.5256 & 36.5448 & 40.46275 & 33.892032 & 36.0998 & 38.3381 \\
\hline
\end{tabular}

Table (4): Parameters Evaluation after zeroing $C\{1,2\}\{1,2\}$ coefficient of size $512 * 512$

\begin{tabular}{|l|c|c|c|c|c|c|c|c|c|}
\hline 512*512 & \multicolumn{3}{|c|}{ scale2 } & \multicolumn{3}{c|}{ scale3 } & \multicolumn{3}{c|}{ Scale4 } \\
\hline & $\begin{array}{c}8 \\
\text { angles }\end{array}$ & $\begin{array}{c}16 \\
\text { angles }\end{array}$ & $\begin{array}{c}32 \\
\text { angles }\end{array}$ & $\begin{array}{c}8 \\
\text { angles }\end{array}$ & $\begin{array}{c}16 \\
\text { angles }\end{array}$ & $\begin{array}{c}32 \\
\text { angles }\end{array}$ & $\begin{array}{c}8 \\
\text { angles }\end{array}$ & $\begin{array}{c}16 \\
\text { angles }\end{array}$ & $\begin{array}{c}32 \\
\text { angles }\end{array}$ \\
\hline Contrast & $1.33 \mathrm{E}+12$ & $1.33 \mathrm{E}+12$ & $1.33 \mathrm{E}+12$ & $1.33 \mathrm{E}+12$ & $1.33 \mathrm{E}+12$ & $1.33 \mathrm{E}+12$ & $1.33 \mathrm{E}+12$ & $1.33 \mathrm{E}+12$ & $1.33 \mathrm{E}+12$ \\
\hline Energy & $4.64 \mathrm{E}+09$ & $4.64 \mathrm{E}+09$ & $4.64 \mathrm{E}+09$ & $4.64 \mathrm{E}+09$ & $4.64 \mathrm{E}+09$ & $4.64 \mathrm{E}+09$ & $4.64 \mathrm{E}+09$ & $4.64 \mathrm{E}+09$ & $4.64 \mathrm{E}+09$ \\
\hline Correlation & 0.99995 & 0.99999 & 0.999996 & 0.99959 & 0.99977 & 0.999888 & 0.9991413 & 0.99949 & 0.99975 \\
\hline MSE & 0.24799 & 0.06571 & 0.019283 & 1.90763 & 1.07304 & 0.516371 & 3.9628334 & 2.32847 & 1.156 \\
\hline PSNR & 60.2411 & 66.0091 & 71.33358 & 51.3805 & 53.8792 & 57.05578 & 48.205341 & 50.5147 & 53.5558 \\
\hline
\end{tabular}




\section{CONTRAST AND ENERGY}

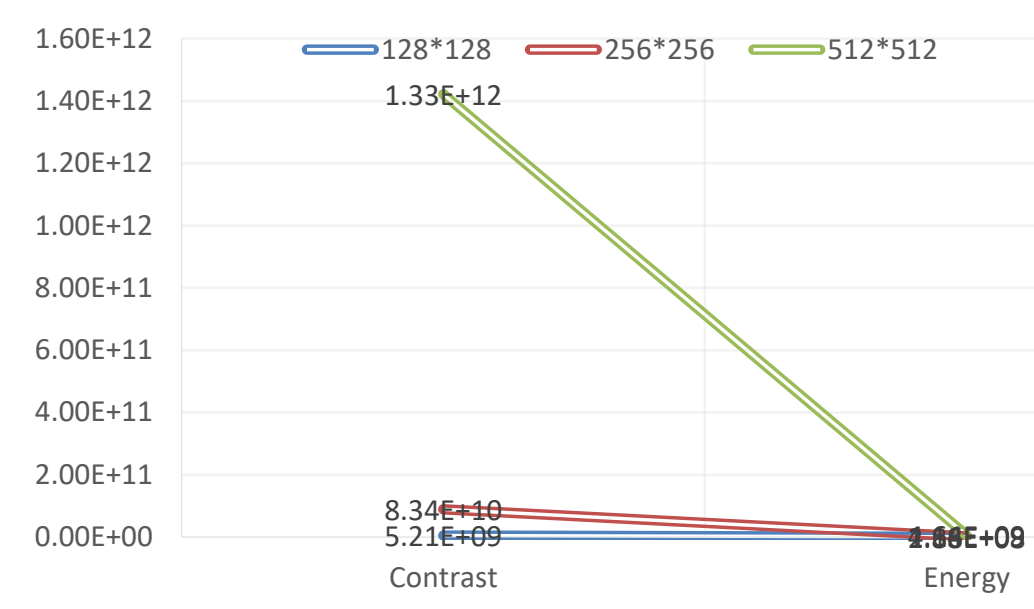

Figure (8): Contrast and Energy for different size of the image

As illustrated above by Figure (8), When resizing the image to a size smaller than 256 , which is $128 * 128$, Contrast and Energy are reduced, while resizing it to the larger size, which is 512*512, Contrast and Energy are increased. Taking into consideration that changing the number of angles or the number of scales of analysis does not affect them.

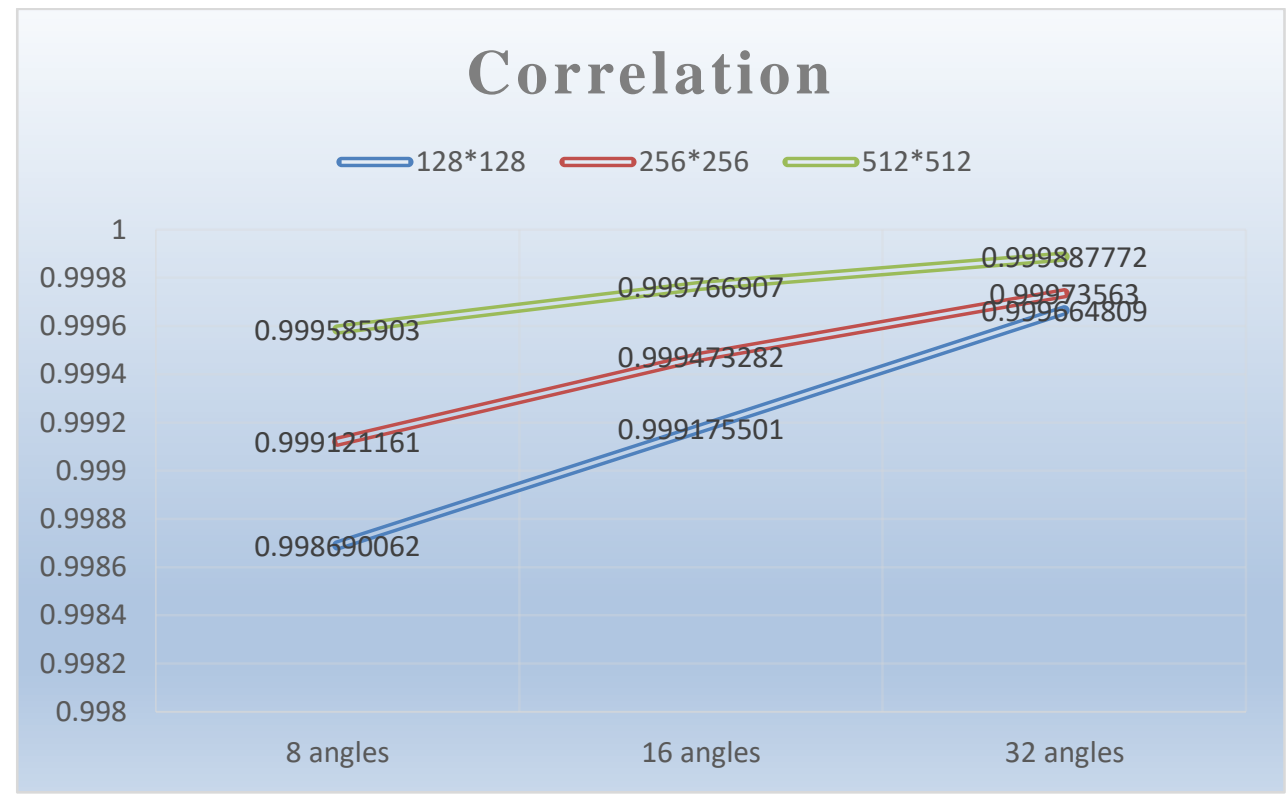

Figure (9): Correlation for different sizes at scale 3

Figure (9) compares Correlation values for different sizes of image for the angles $(8,16,32)$ within scale 3 , for example, but is not limited to, which includes the following: The larger the image size, the greater the convergence between the original image and the recovered image from the Curvelet transform and Fan filter. 


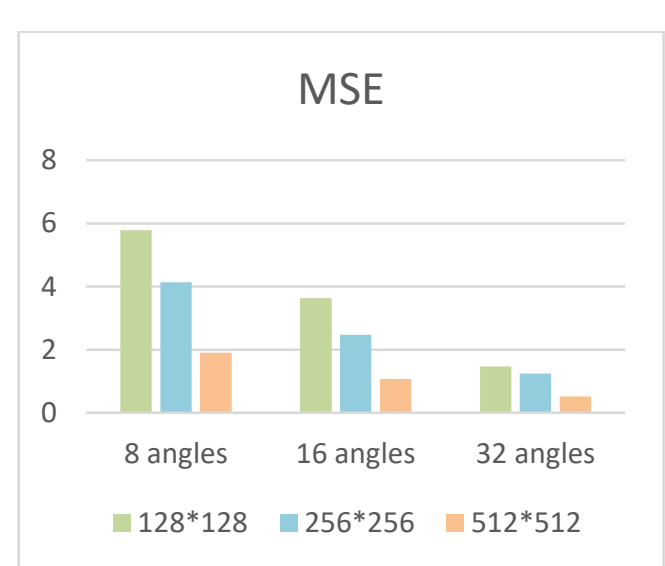

(a)

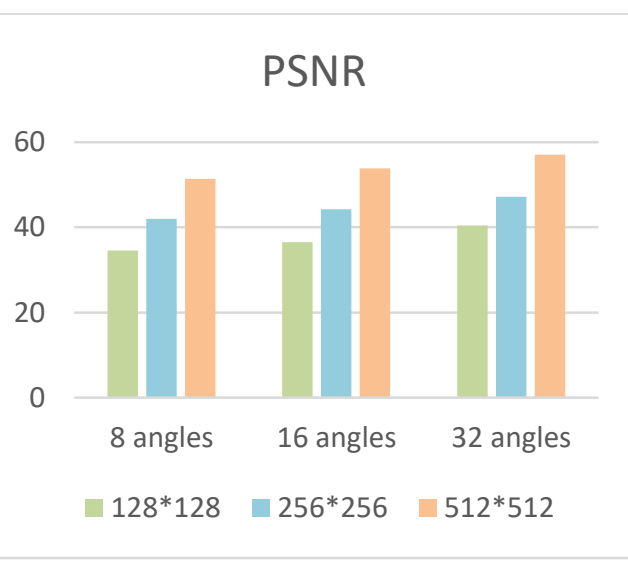

(b)

Figure (10): (a) MSE of different sizes at scale 3;(b): PSNR of different sizes at scale 3

According to Figure (10), the work of the algorithm in MSE and PSNR values at different sizes of the image is achieved by the following: as the larger the image size, MSE decreases while PSNR increases.

\section{Conclusion}

From the discussion seen, it is proved that the effect of the directions of the Fan filter is very clear on the reconstructed image, which means that the dropped frequencies from the reconstructed image which, reflected by the Fan filter have a variance on the metrics parameters. The results show that dropping the coefficients of high frequencies which affect the image edges has a clear effect on the reconstructed image energy when the Curvelet level change. Also, the image size has less effect than that of the Curvelet scale (level). When the angles of the Fan filter changed, the results showed that the effect on the retrieved image is very clear on vertical and horizontal components. 


\section{REFERENCES}

[1] Abdalla M.Hambal, Zhijun P. \& Faustini L.Ishabailu. (2017). Image Noise Reduction and Filtering Techniques. International Journal of Science and Research (IJSR). ISSN: 2319-7064. Vol. 6, Issue 3.

[2] Al-Ani M.\& Khalaf A. (2013). Image Information Retrieval Using Wavelet And Curvelet Transform. International Journal of Soft Computing And Engineering (IJSCE) ISSN: 2231-2307. Vol.3. Issue-1.

[3] Hui Zhang, Xu Ma \& Yanshan Tian. (2020). An Image Fusion Method Based on Curvelet Transform and Guided Filter Enhancement. Mathematical Problems in Engineering.

[4] Jie Hu, Ying Li \&Yu Jia. (2012). Automatic SAR Image Enhancement Based on Curvelet Transform and Genetic Algorithm. International Conference on Intelligent Science and Intelligent Data Engineering. pp. 326-333.

[5] Kaizhi Wu, Xuming Zhang \& Mingyue. (2013). Curvelet based nonlocal means algorithm for image denoising. International Journal of Electronics and Communications. Vol. 68, Issue 1, P. 37-43.

[6] Karam Abdullah, Eman Abdullah \& Khalil I Alsaif. (2019). High pass filter based on curvelet transform coefficients. 2nd International Science Conference. IOP Conf. Series: Journal of Physics: Conf. Series 1294(2019)042005

[7] Khalil Alsaif and Huda Qassab_Bashi. (2013). CONTOURLET TRANSFORMATIONS FOR STUDYING COLOR CAST IN DIGITAL IMAGE BASED ON DIFFERENT COLOR MODELS. International Journal of Information Technology and Business Management, ISSN 2304-0777, Vol.14, No.1.

[8] Khalil Alsaif and Montaha Alsarraj. (2013). NEW TECHNIQUE FOR SKEW ANGLE DETECTION OF TEXT IN IMAGE DOCUMENT. Corpus ID: 123269484. Mathematics.

[9] Li Y., Wangy. \& Xiao R. (2013). Curvelet Based Image Compression Via Core Vector Machine. Elsevier Optik 124 (2013) 4859- 4866.

[10] Majed Al-Dwairi, Ziad Alqadi, Amjad AbuJazar \& Rushdi Abu Zneit. (2010). Optimized True Color Image Processing. World Applied Science Journal 8 (10):1175-1182, ISSN 1818-4952.

[11] Meaad M. Salih, Shatha M. Ramadhan \& Manar A. Al-Abaji. (2019). Multi approach for finger print recognition based on transformation methods. In AIP Conference Proceedings 2096, 020017.

[12] Minh N. Do and Yue M. Lu. (2011). Multidimensional Filter Banks and Multiscale Geometric Representations. Vol. 5, No. 3. 157-264. DOI: $10.1561 / 2000000012$.

[13] Mohamed Elhabiby, Ahmed Elsharkawy \& Naser El-Sheimy. (2012). Second Generation Curvelet Transforms Vs Wavelet Transforms And Canny Edge Detector For Edge Detection From Worldview-2 Data. International Journal Of Computer Science \& Engineering Survey (IJCSES) Vol.3, No.4. 
[14] Nagham S. Al-lella and Khalil Alsaif. (2012). Data Hiding In Contourlet Coefficients Based On Their Energy. Journal of university of Anbar for pure science: Vol.6: NO.2. ISSN: 1991-8941.

[15] Nilima, D. Maske, Wani, V. Patel. (2012). Comparison of Image Compression Using Wavelet For Curvelet transform \& Transmission Over Wireless Channel. International Journal Of Scientific And Research Publications, Vol.2, Issue 5, ISSN: $2250-3153$.

[16] Rajakumar and Muttan. (2013). A Framework For Mri Image Retrieval Using Curvelet Transform And Euclidean Distance. Journal Of Computer Science. 9 (3): 285-290. ISSN: 1549-3636. Doi:10.3844/Jcssp.

[17] Ren C. Jianguo Y. (2012). A Novel Color Microscope Image Enhancement Method Based On HSV Color Space And Curvelet Transform. IJCSI International Journal Of Computer Science Issues. Vol. 9. Issue 6. No 2. ISSN: 1694-0814.

[18] Sangeetha T. and Saradha A. (2013). An Efficient Technique To Enhance Mammogram Image Using Curvelet Transform. International Journal Of Computer Science Engineering And Information Technology Research (IJCSEITR). ISSN: 2249-6831., Vol. 3. Issue 1., 155-164.

[19] Shadi Alzubi, Naveed Islam \& Andmaysam Abbod. (2011). Multiresolution Analysis Using Wavelet, Ridgelet, And Curvelet Transforms For Medical Image Segmentation. International Journal of Biomedical Imaging. Volume 2011. Article ID 136034. 18 pages. doi:10.1155/2011/136034.

[20] Tirveedi P., Pullarao Ch. (2014). An Efficient Cum Improved Resolution Enhancement Using Zero Padding and Curvelet Transforms. International Journal of Engineering Trends And Technology (IJETT) - Vol.15 Number 1.

[21] Vaghela A. (2013). Image Restoration Using Curvelet Transform. Journal Of Information, Knowledge And Research In Electronics And Communication Engineering. ISSN: 0975 - 6779, Vol.02, Issue - 02 Page 783-787.

[22] Wu K., Zhang X. \& Ding M. (2014). Curvelet Based Nonlocal Means Algorithm For Image Denoising. International Journal of Electronics And Communications (AEÜ). Int. J. Electron. Commun. (AEÜ) 68, PP: 37-43. 